REVESCO. Revista de Estudios Cooperativos ISSN: $1885-8031$

http://dx.doi.org/10.5209/REVE.59768

\title{
La intercooperación representativa en España. Evolución y expansión
}

\author{
Antonio José Macías Ruano ${ }^{1}$
}

Recibido: 30 de agosto de 2017 / Aceptado: 6 de marzo de 2018

Resumen. En el presente trabajo se revisa el proceso legislativo nacional de la inserción del principio cooperativo de cooperación entre cooperativas desde su vertiente representativa, señalando las soluciones que ha ido dando el legislador nacional al asociacionismo cooperativo, así como otras políticas legislativas actuales que, de forma indirecta, potencian la intercooperación representativa, así como señalar la presente interrelación de las sociedades cooperativas con otras estructuras jurídicas con las que concurre en el mercado para el mismo papel de defensa de sus intereses y proyección, produciéndose una simbiosis entre estructuras que en principio resultan antagónicas, pero unidas por el interés.

Palabras clave: Intercooperación; Asociaciones Cooperativas; Uniones; Federaciones; Confederaciones.

Claves Econlit: A13; P13; L52; K22.

\section{[en] The representative inter-cooperation in Spain. Evolution and expansion}

\begin{abstract}
In this paper aims at reviewing the national legislative process about the insertion cooperative principle of cooperation among cooperatives from its representative aspect, pointing out the answers which have been given by the national legislator to the inclination to cooperative association, as well as other current legislative policies that, indirectly, promote representative cooperation, in addition it will be noted the present relationship between cooperative societies with other legal structures with which compete in the market for the same defensive role of their attention and projection, creating a symbiosis between former opposing entities, joined by business.
\end{abstract}

Keywords: Inter-cooperation; Cooperative Associations; Unions; Federations; Confederations.

Sumario. 1. Introducción. 2. Concreción del principio de integración cooperativa y su interrelación con otros principios. 3. Evolución en la formulación del principio internacional de Cooperación entre cooperativas y su reflejo legislativo nacional hasta el actual régimen jurídico. 4. Concreción actual y proyección legislativa nacional en torno a la integración representativa. 5. Otras fórmulas legislativas e institucionales de la intercooperación representativa fuera del ámbito cooperativo. 6. Conclusiones. 7. Referencias bibliográficas.

Cómo citar: Macías Ruano, A.J. (2017) La intercooperación representativa en España. Evolución y expansión. REVESCO. Revista de Estudios Cooperativos, Monográfico, № 126, pp. 133-153. DOI: 10.5209/REVE.59768.

$1 \quad$ Universidad de Almería, España

Dirección de correo electrónico: ajmacias@ual.es 


\section{Introducción}

Actualmente en el desarrollo legislativo nacional del sexto principio internacional cooperativo de cooperación entre cooperativas se distinguen dos perspectivas, la integración económica y la integración representativa, tal y como señala, literalmente, el artículo 108 de la Ley 27/1999, de 16 de julio, de Cooperativas ${ }^{2}$.

A la intercooperación económica se le suele dedicar una mayor atención que a la representativa tanto por parte del legislador, como también por la doctrina, quizá por la imperiosa necesidad de aumentar el volumen y presencia de sociedades cooperativas que, en un mercado cada vez más global y bajo parámetros de competitividad en una economía de escala, produzcan con eficiencia, aportando productos y servicios al mercado de forma más relevante (Cano Ortega, 2015: 69). Muestra de está preocupación es la publicación de normas como la Ley 13/2013, de 2 de agosto, de fomento de la integración de cooperativas y de otras entidades asociativas de carácter agroalimentario. No obstante, el enunciado del principio internacional al que nos referimos se ajusta, quizá con mayor claridad, a lo que se concreta como la intercooperación representativa o "sociopolítica" (Fici, 2014), esto es, la potenciación de estructuras de colaboración más allá de la puramente productiva o económica entre cooperativas para que promocionen a todos los niveles políticos, empresariales y sociedad civil, las condiciones necesarias para el desarrollo y potenciación de este tipo de estructura jurídica, y así puedan defender sus intereses y velar por mantener estímulos y condiciones favorables para su presencia, participación y expansión en el mercado.

En el presente trabajo nos vamos a centrar en el desarrollo legislativo e institucional del proceso de integración cooperativa en su vertiente representativa en España para determinar su singularidad, utilidad y proyección en el puro marco del cooperativismo, si la tuvieran, y para comprobar si el sexto principio cooperativo actúa de «ancla que impide que el barco cooperativo derive en exceso impulsado por los vientos o arrastrado por las corrientes de la economía capitalista ... y pueda conservar su propia identidad» (Vargas Vasserot, 2016: 13).

\section{Concreción del principio de integración cooperativa y su interrelación con otros principios}

Debemos partir de un concepto de intercooperación como toda relación de coordinación, en plano de igualdad y sin subordinación, establecida entre cooperativas sin que medie la pérdida de la personalidad jurídica, y entendiendo la de carácter representativo como la que tiene por objeto el impulso del movimiento cooperativo y de defensa y promoción de los intereses de sus cooperativas asociadas (Sánchez Pachón, 2015: 10).

Este concepto se recoge, a nivel institucional internacional, en el XXXI Congreso de la Alianza Cooperativa Internacional celebrado en 1995 en

2 Art. 108 L. 27/1999: «Se reconoce como tarea de interés general... la promoción, estímulo y desarrollo de las sociedades cooperativas y de sus estructuras de integración económica y representativa». 
Manchester, donde se redefinieron los llamados principios -y valorescooperativos. Como sexto principio se fijó el de "Cooperación entre cooperativas", entendido como aquel por el que «Las cooperativas, para servir mejor a los intereses de sus miembros y sus comunidades, deben colaborar por todos los medios con otras cooperativas a los niveles local, nacional e internacional».

Este principio no se conceptúa, como el resto de ellos, como estanco y aislado, sino que tiene relación directa con enunciados de otros principios cooperativos puesto que ninguno es independiente el uno del otro, estando sutilmente unidos (De Miranda, 2014: 159). La intercooperación cooperativa no solo es una proyección ligada con el sexto principio sino que también está relacionada con el primero de los enumerados por la Declaración sobre la identidad Cooperativa realizada por la A.C.I. en el mentado Congreso de 1995, esto es, con el principio de libre adhesión y baja voluntaria de socios, que exige que la organización debe procurar y potenciar la entrada de nuevos socios interesados, aunque con la condición de que cumplan con los requisitos exigibles a cualquiera de los socios de la cooperativa, reflejo de la labor expansiva y difusiva (García Gallardo: 1979: 119) que propugna el movimiento cooperativo. La proyección del movimiento cooperativo y de su materialización societaria, la sociedad cooperativa, «desde el inicio ya constituye una federación libre de unidades económicas elementales (personas, familias, explotaciones rurales o artesanas)» (Martínez Charterina, citando a Colombain, 1990: 45), puesto que debe procurar la incorporación -integración- de nuevos socios, que serían las unidades productivas que se "federan" en la cooperativa, y de ahí ampliando la tendencia expansiva a otras fórmulas de integración para proyectar la ideología de generación de riqueza basada en la actividad, en la gestión o control democrático de la estructura societaria, donde prevalece el socio sobre el capital, de tal modo que se visibilice, expanda y refuerce la fórmula empresarial cooperativa.

Igualmente, la intercooperación representativa se relaciona con el quinto principio internacional cooperativo de educación, formación e información, que proviene de los originalmente fijados en los estatutos de la Cooperativa de los Pioneros de Rochdale, habiendo sido calificado como «la regla de oro del cooperativismo», y al que «dentro de la historia de la cooperación se le ha dado una importancia constante» (Aranzadi Tellería, 1976: 74).

Con la reformulación de los principios cooperativos que hizo la A.C.I. en su Congreso de 1995, se perfila este principio de educación, formación e información, entre otros contenidos, como aquel por el que «Las cooperativas informan al público en general, particularmente a jóvenes y creadores de opinión, acerca de la naturaleza y beneficios del cooperativismo» ${ }^{3}$. Con el contenido y concepción que de este principio ha hecho la A.C.I., se abarca tanto al ámbito interno de la sociedad cooperativa como su proyección hacia el exterior, puesto que, «por un lado la educación y la formación son acciones que se tienen en cuenta de puertas para adentro; por otro lado, la información se propugna con una función publicitaria y promotora». (García-Gutiérrez Fernández, 1995: 97).

\footnotetext{
Definición obtenida de la página web oficial de la A.C.I. para las Américas con la dirección http://www.aciamericas.coop/Principios-y-Valores-Cooperativos-4456.
} 
Por otro lado, en el ámbito interno de la sociedad cooperativa el legislador nacional ha previsto una herramienta financiera propia que caracteriza a la cooperativa, el Fondo de Educación y Promoción cooperativo, que desde la reforma operada por la Ley 13/2013, de 2 de agosto, en la Ley 27/1999, de Cooperativas permite que sea aportado a la unión o federación a la que esté asociada (Macías Ruano, 2015).

Igualmente, el quinto principio se proyecta extramuros de la cooperativa pretendiendo la mejora del nivel educativo del entorno donde desarrolla su acción económica, potenciando esta fórmula de desarrollo de la actividad, procurando nuevos fieles en el marco de su labor de extensión del movimiento cooperativo como alternativa a la realidad económica capitalista dominante. Y esa proyección externa se ha de hacer tanto a nivel individual de cada cooperativa en su entorno, como también a nivel colectivo, de integración de sociedades cooperativas que visibilicen, presenten, defiendan y proyecten sus derechos e intereses, haciendo partícipes a la comunidad la fórmula cooperativa de generación de riqueza. Cuando las cooperativas se agrupan en entidades asociativas de representación, consiguen el acceso a escenarios de decisión a los que no tendrían acceso de forma individualizada, aumentando la visibilidad y proyección externa del movimiento cooperativo para conseguir sus objetivos de defensa y promoción, que es uno de los objetivos del principio de formación e información.

\section{Evolución en la formulación del principio internacional de Cooperación entre cooperativas y su reflejo legislativo nacional hasta el actual régimen jurídico}

No obstante la diferenciación entre la intercooperación económica y la representativa, con carácter general, sin distinguir por ahora las dos vertientes, ha de señalarse que fue en el XXIII Congreso de la Alianza Cooperativa Internacional, celebrado en Viena en 1966 -momento en el que se redefinen los principios del cooperativismo fijados en el anterior Congreso de París de 1937- donde por primera vez se recoge como principio cooperativo el de "Cooperación entre cooperativas", también denominado principio de "Integración cooperativa", y que fue enunciado por la A.C.I. como: "Las cooperativas, para servir mejor a los intereses de sus miembros y sus comunidades, deben colaborar por todos los medios con otras cooperativas a los niveles local, nacional e internacional». Este principio se deriva del tenor de los propios estatutos de la Cooperativa de los Pioneros de Rochdale de 1844, cuando establece en el párrafo sexto de su artículo primero, que «Desde el momento que sea posible esta sociedad emprenderá la organización de las fuerzas de la producción, de la distribución, de la educación y del gobierno, o dicho en otras palabras, el establecimiento de una colonia que se baste a sí misma y en la que se unirán los intereses, o bien prestará ayuda a otras sociedades para establecer colonias de esa clase» (De Miranda, 2014: 158), y no es más que consecuencia del espíritu apostólico del movimiento cooperativo para crear una red de desarrollo de las cooperativas más allá del ámbito territorial que abarque su capacidad de acción, puesto que «su finalidad última es lograr la expansión del cooperativismo como un movimiento donde participen libremente 
las cooperativas en una línea de integración progresiva desde niveles regionales y nacionales hasta un nivel internacional» (Alonso Sebastián, 1982: 156).

Con anterioridad al Congreso de Viena de 1966, prácticamente desde la consolidación del movimiento cooperativo, esto es, «desde mediados del siglo XIX se habían ido formando las federaciones de cooperativas y... en 1895 se constituyó la Alianza Cooperativa Internacional, terminando con ella lo que denominamos el movimiento cooperativo, y que desde finales del siglo XIX se perseguía la idea que se acabó plasmando en el sexto principio» (Martínez Charterina, 2012: 139). Por tanto, pese a que el principio cooperativo no quedara fijado como tal por la A.C.I. hasta el Congreso de Viena de 1966, lo cierto es que esta proyección siempre ha estado latente y ha tenido relevancia tanto jurídica como institucional (Martínez Charterina, 1990: 21-23).

En el ámbito nacional español, en un proceso de surgimiento y consolidación del movimiento cooperativo, se fueron formando distintas federaciones territoriales y la nacional, que se incorporan, a su vez, a la máxima expresión del asociacionismo representativo, la A.C.I. Así, en 1920 se adhiere a la A.C.I. la Federación de Cooperativas Catalanas, y en 1929 lo hace la Federación Nacional de Cooperativas de España. Igualmente se publicaron disposiciones legales tendentes al desarrollo de este principio con anterioridad a la fecha de fijación del mismo en 1966. Con el Decreto-Ley 4 de julio de 1931, Ley de Cooperativas, y su Reglamento -Decreto de 2 de octubre de 1931- se reconoce la libre federación al señalar que «Las cooperativas podrán constituir Uniones o Federaciones para defender sus intereses comunes y para mejor realización de sus propios fines $\rangle^{4}$, dando carta de naturaleza a la asociación representativa para la proyección y protección de sus intereses y modelos.

Tras el Golpe de Estado de 1936, y en plena Guerra Civil, por el bando "nacional" se publica la Ley 27 octubre 1938, Cooperativas, modificando la anterior de la República de 1931 y su Reglamento, que, «sin derogar el contenido funcional de la misma, la desposeía de todos sus elementos de carácter democrático, substituyéndolos por un sistema autoritario y jerarquizado» (Aymerich Cruells, 2008: 29), y con una vocación claramente provisional, circunstancia que fue refrendada por el escaso tiempo en que tardó en publicarse la primera Ley franquista de cooperativas, la Ley de 2 de enero de 1942. En la Ley de 1938 se regula de forma más extensa la integración representativa de las cooperativas para limitar su crecimiento y ubicarlas dentro del control del Ministerio de Organización y Acción Sindical, embrión político-administrativo de lo que sería posteriormente el denominado "Sindicato Vertical", haciendo desaparecer las Federaciones y Confederaciones, y remodelando las Uniones de Cooperativas que estarán bajo control administrativo de las denominadas Zonas

$4 \quad$ Así se recoge en el art. 37 del Decreto-Ley de 4 de julio de 1931, desarrollado por los artículos 77 y 78 del Reglamento -Decreto de 2 de octubre de 1931-, concretando que «Cinco o más Cooperativas locales o comarcales podrán constituir una Unión o una Federación provincial. Ocho o más Cooperativas locales o comarcales podrán constituir una Unión o una Federación cuya acción se extienda a más de una provincial./ Tres o más entidades provinciales, interprovinciales y del distrito podrán constituir una entidad del orden superior...» 
Económicas ${ }^{5}$, procurando una vigilancia política sobre la base de las uniones de cooperativas, sin organizaciones más complejas y potentes.

Terminada la Guerra Civil, y en pleno período del denominado "franquismo autárquico", donde, «siguiendo la herencia recibida del modelo económico nacionalista y los postulados de la doctrina falangista, fue de rechazo total a todo lo que significase relacionarse con el exterior») (Fernández Navarrete, 2005: 55), se publica la Ley de Cooperativas de 1942, eludiendo toda referencia a una posible integración intercoope-rativa que pueda suponer una potenciación institucional de estas sociedades de base tanto en el plano nacional, como, por supuesto, en el internacional. Con la instauración dos años antes -el 26 de enero de 1940- de la Organización Sindical Española (Sindicato Vertical), se impone el encuadramiento de las cooperativas en Uniones que se organizan como estructuras de la Organización Sindical del Estado: "Las cooperativas formarán Uniones a través de la Obra Sindical de Cooperación" (art. 46), y estas uniones irán formando escalonadamente las territoriales, las interterritoriales y la nacional, con la misión de «promover, dirigir y, en su caso, desempeñar las actividades cooperativas en las ramas respectivas» (art. 50) y, siempre contarán con «un Consejo de vigilancia, que será nombrado por el Delegado Nacional de Sindicatos, a propuesta de la Obra Sindical de Cooperación» en las Uniones territoriales, y en las nacionales será nombrado «por el Ministro Secretario General del Movimiento, a propuesta del Delegado Nacional de Sindicatos» (art. 52). Esta estructura de control políticoadministrativa se desarrolla en el Título II del Reglamento de Cooperativas aprobado por el Decreto de 11 de Noviembre de 1943, fijando la obligatoriedad de las Uniones de cooperativas (desarrollo del art. 52 de la Ley), con lo que ello conlleva de fiscalización e intervención pública en el ámbito de la intercooperación representativa de éstas, lo que supuso de hecho la exclusión de los miembros españoles de la A.C.I. dado el intervencionismo público y falta de autonomía e independencia, y la conculcación del quinto principio cooperativo vigente en ese momento de neutralidad política y religiosa ${ }^{6}$, fijado por la Aliana Cooperativa Internacional en 1937.

Celebrado el Congreso de la A.C.I. de Viena de 1966, y fijados los nuevos principios cooperativos internacionales, en nuestro régimen jurídico interno se

5 Disponía el artículo 10 de la Ley de 27 de octubre de 1938, que «En sustitución de las Federaciones y Confederaciones que reconoce la Ley vigente, las Cooperativas de cada provincia, podrán reunirse siguiendo razones de conveniencia y armonía para la mejor defensa de sus intereses, constituyendo una "Unión Provincial de Cooperativas"./ Las "Uniones Provinciales de Cooperativas", podrán a su vez, agruparse, integrando una Unión de Cooperativas de Zona Económica”... determinadas por el Ministerio de Organización y Acción Sindical... Las Uniones de Cooperativas de Zona Económica" podrán formar Uniones Nacionales de Cooperativas». Posteriormente, en su artículo 11 hace referencia a la Jefatura de las Uniones Provinciales que será designada por la Asamblea, pero que podrá ser vetada por el «Ministro de Organización y Acción Sindical». (art. 6).

6 De hecho, en 1942, la A.C.I., pese a que consideraba la neutralidad política y religiosa como un principio secundario que no constituía, por sí, una condición de adhesión a la misma (De Miranda, 2014: 154), da de baja a las dos organizaciones españolas que formaban parte de la Alianza -La Federación de Cooperativas Catalanas y la Federación Nacional de Cooperativas de España- como consecuencia de la publicación en España de la Ley de Cooperación de este año, ya que se obligaba a las federaciones, a partir de entonces uniones territoriales, a estar gobernadas por un jefe nombrado por la Obra Sindical de la Cooperación, que debía militar a la Falange y era obligatorio tener adscrito a un sacerdote. Vid. Confederació de Cooperatives de Catalunya, en "De l'estat liberal al franquisme", 2016, disponible en http://www.cooperativescatalunya.coop/index.php/ca/observatori/historia. 
publica la Ley 52/1974, de 19 de diciembre, General de Cooperativas, donde se inserta, aunque de modo parcial, el principio de integración cooperativa proclamado por la Alianza Cooperativa Internacional. En el artículo $2.1 \mathrm{~g}$ ) de la Ley española se prevé como carácter propio de las cooperativas "La colaboración con otras entidades cooperativas para el mejor servicio de sus intereses comunes", aunque «omitiendo la referencia a los niveles territoriales de cooperación, para evitar seguramente el escollo que significaba en aquella época un compromiso de colaboración de las cooperativas españolas en el plano internacional» (Alonso Sebastián, 1982: 157), puesto que, pese al aperturismo pretendido por la dictadura, sigue viéndose con recelo cualquier relación económica o política con el exterior.

Tras el agotamiento del régimen dictatorial, con la llegada de la democracia y la aprobación de la Constitución de 1978, a las cooperativas se les da un lugar relevante en la política legislativa nacional, señalando el artículo 129 C.E. la necesidad de que los poderes públicos fomenten «mediante una legislación adecuada, las sociedades cooperativas». Esta declaración jurídica del más alto nivel legal hace que se busquen fórmulas de desarrollo legislativo de las Cooperativas que cumplan con las necesidades nacionales y con el marco internacional. Pero en la propia configuración del Estado diseñado en al Constitución Española, surge un obstáculo grave en la búsqueda de fórmulas del desarrollo legislativo "adecuado" para las cooperativas, el Estado de las Autonomías, y el problema se inicia a partir de la aprobación del Estatuto de Autonomía del País Vasco, en el que se asume la competencia autonómica exclusiva en materia cooperativa, estatuto al que siguieron el de Cataluña, Andalucía, Valencia y Navarra. En la génesis del marco autonómico nacional, además de los Estatutos en los que se asigna la competencia exclusiva en materia de cooperativas a su respectiva comunidad, en otros Estatutos de autonomía se asumieron competencias de desarrollo y ejecución en esta materia como los de Galicia o Islas Baleares, o solo de ejecución como el de Canarias (Alfonso Sánchez, 2009: 20). Pero, en cualquier caso, finalmente, por la Ley Orgánica 9/1992, de 23 de diciembre, de Transferencia de competencias a Comunidades Autónomas que accedieron a la autonomía por la vía del artículo 143 de la Constitución, el Parlamento nacional traspasó a todas las comunidades autónomas las competencias legislativas en materia de cooperativas. Todos estos precedentes legislativos dieron lugar a publicar, primero la Ley 1/1982, de 11 de febrero, sobre Cooperativas vascas, y posteriormente la Ley 4/1983, de 9 de marzo, de Cooperativas de Catalunya, y así, sucesivamente, hasta un total, actualmente, de dieciséis normas sustantivas autonómicas de cooperativas "adecuadas", que conviven con la de ámbito nacional -aplicable en el ámbito territorial de Canarias, Ceuta y Melilla y a las cooperativas que tiene su marco de actuación en más de una comunidad autónoma y no de forma principal en cualquiera de ellas-.

No obstante el proceso de desarrollo legislativo autonómico en materia de cooperativas, tras la instauración de la democracia, en el ámbito estatal se publica la Ley 3/1987, de 3 de abril, General de Cooperativas que deroga la anterior de 1974, desapareciendo la enumeración puntual de los principios proclamados por la A.C.I. como notas configuradoras de las cooperativas, aunque haciendo una expresa mención a tales principios en vigor, pero mediatizando su desarrollo conforme señale la propia disposición legal. Así el artículo 1.3 de la Ley de 1987 
dispone que «Las Cooperativas se ajustarán en su estructura y funcionamiento a los principios formulados por la Alianza Cooperativa Internacional en los términos establecidos en la presente Ley». Es decir, que el principio de integración cooperativa fijado por la A.C.I. en 1966, en toda su extensión, debe conformar la estructura y funcionamiento de las cooperativas en España desde 1987, aunque condicionada por el desarrollo legislativo que hace la propia norma. En cualquier caso, debe tenerse presente, como hemos señalado, que a la fecha de publicación de esta Nueva Ley General de Cooperativas (1987) ya se han publicado las leyes autonómicas de cooperativas del País Vasco, de Cataluña, de Andalucía y de Valencia, con lo que el tenor de la aplicación de los principios cooperativos de la A.C.I. tal y como se señala en la Ley de 1987 para las cooperativas españolas, no comprende a todas las que se constituyen o funcionan en aquel momento en España.

No obstante, pese a la prevención de reconocimiento de los principios cooperativos dictados por la A.C.I. que se condicionan al desarrollo legislativo que haga el legislador, el tratamiento del principio de integración cooperativa en la Ley 3/1987, General de Cooperativas, «está acogido... como todos, de modo general en el... art. 1-3 de la misma; y de modo particular, en los arts.: 7, 9, 29, 30, 43, 47, 148, 149 y en los arts. 158-161» (Sanz Jarque, 1994: 128). En todos estos artículos se contemplan fórmulas de integración económica y de asociacionismo cooperativo formando Uniones, Federaciones y Confederaciones de Cooperativas (art. 158). Hecho de especial relevancia es que en esta norma ya se hace un distingo expreso entre los mecanismos de integración económica, y los de integración representativa (art. 150) $)^{7}$.

Con el XXXI Congreso de la Alianza Cooperativa Internacional celebrado en Manchester en 1995, se vuelven a redefinir los valores y principios cooperativos, fijándose como sexto principio el de "Cooperación entre cooperativas" conceptuándolo, al igual que se hizo en el Congreso de Viena de 1966, como aquel por el que «Las cooperativas sirven a sus socios lo más eficazmente posible y fortalecen el movimiento cooperativo trabajando conjuntamente mediante estructuras locales, nacionales e internacionales».

\section{Concreción actual y proyección nacional en torno a la integración representativa}

\subsection{Como principio en el ámbito nacional}

Fijado el principio internacional cooperativo de Cooperación entre cooperativas en el Congreso de la A.C.I. de 1995, manteniendo el mismo concepto del anterior de 1966, en España se publica la vigente Ley 27/1999, de 16 de julio, de Cooperativas, que viene a derogar la anterior de 1987. En lo que respecta a este principio de cooperación entre cooperativas no se recoge como enunciado singular

7 Disponía el art. 150 de la L. 3/1987, General de Cooperativas que «De conformidad con el mandato contenido en el artículo 129.2 de la Constitución Española, el Estado reconoce como tarea de interés público la promoción, estímulo y desarrollo de las Sociedades Cooperativas y de sus estructuras de integración económica y representativa, cuya libertad y autonomía garantiza». 
y concreto en el texto legal de la Ley de 1999, puesto que, junto con los demás principios cooperativos que fija la A.C.I. desaparecen de la literalidad del texto normativo, al igual que ya hizo el Legislador nacional en la anterior norma de 1987, limitándose a hacer una referencia a los principios cooperativos enunciados por la A.C.I. de forma genérica tanto en la exposición de motivos ${ }^{8}$, como en su artículo primero 9 . Esta omisión literal de los principios cooperativos como principios jurídicos dificulta la asunción de los mismos puesto que podría entenderse que «los principios cooperativos...tienen un carácter meramente ético $y$, por lo tanto, carente de fuerza jurídica vinculante... [pudiendo interpretarse que sólo] El reconocimiento de los principios cooperativos como principios jurídicos explícitos dota a los principios cooperativos de fuerza normativa» (Moreno Fontela, 2017: 7-8 ${ }^{10}$.

En cualquier caso, entendiendo la intercooperación, como hemos señalado anteriormente y a los efectos del presente trabajo, como toda relación de coordinación, en plano de igualdad y sin subordinación, establecida entre cooperativas sin que medie la pérdida de la personalidad jurídica, y entendiendo la de carácter representativo como la que tiene por objeto el impulso del movimiento cooperativo y de defensa y promoción de los intereses de sus cooperativas asociadas (Sánchez Pachón, 2015: 10), ésta, la intercooperación representativa, se corresponde con el enunciado del Título III de la Ley 27/1999, de 16 de julio, de Cooperativas (arts. 117 a 120) "Del Asociacionismo Cooperativo"11, donde se prevé la creación de Uniones, Federaciones y Confederaciones de Cooperativas, aunque sin excluir ninguna «otra fórmula asociativa conforme al derecho de asociación $\gg^{12}$ (art. 117 L.C.). Esta forma de integración o relación intercooperativa

8 Señala la exposición de motivos de la Ley 27/1999 que «Los valores éticos que dan vida a los principios cooperativos formulados por la alianza cooperativa internacional, especialmente en los que encarnan la solidaridad, la democracia, igualdad y vocación social tienen cabida en la nueva Ley que los consagra como elementos indispensables para construir una empresa viable con la que los socios se identifican al apreciar en ella la realización de un proyecto que garantiza su empleo y vida profesional»

9 Señala el artículo $1^{\circ}$ de la vigente Ley 27/1999, de Cooperativas, que «la cooperativa es una sociedad constituida por personas... conforme a los principios formulados por la alianza cooperativa internacional, en los términos resultantes de la presente Ley».

10 En sentido contrario Fici entiende que tras la Recomendación de la O.I.T. 193/2002, los principios de la ACI son fuente formal de derecho cooperativo (FICI, 2014: 110). Por otro lado, hay autores que opinan que los principios cooperativos internacionales son "fuente material" de la legislación cooperativa (Alfonso Sánchez, 2015: 59). En un sentido absolutamente divergente, hay autores que consideran que los principios cooperativos no pueden siquiera considerarse como elementos esenciales del concepto de sociedad cooperativa, incluso que si en las leyes cooperativas, históricamente, se han recogido estos principios, se ha hecho más por inercia que por verdaderas necesidades sentidas por las propias cooperativas (Santos Domínguez, 2015).

11 Igualmente recogido en la anterior ley de 1987 con el mismo epígrafe y en los artículos 158 a 161.

12 No obstante la mención al "derecho de asociación", si se entiende referido al régimen jurídico que regula este derecho contenido en la Ley Orgánica 1/2002, de 22 de marzo, reguladora del Derecho de Asociación, solo será como mero referente por analogía, no como estructura legalmente exigible, puesto en que en su artículo $1^{\circ}$, donde la norma fija su objeto y ámbito de aplicación, en sus apartados $2^{\circ} \mathrm{y} 4^{\circ}$ excluye a las estructuras que estén sometidas a un régimen asociativo específico, y de forma particular a las cooperativas y las que se rijan por disposiciones relativas al contrato de sociedad. Las uniones, federaciones y confederaciones de cooperativas, se traten o no de sociedades cooperativas, lo cierto es que, por un lado tienen un régimen jurídico específico tanto a nivel nacional como autonómico, y por otro lado todas las fórmulas de asociacionismo representativo previstas en la legislación cooperativa adquieren personalidad jurídica propia con estructura orgánica, incorporación de estatutos, e inscripción en el Registro de Cooperativas, estructura propia de cualquier sociedad y, en particular, de las cooperativas. 
no busca directamente la gestión empresarial y la obtención de réditos inmediatos de sus miembros, sino una unión de sujetos con fines y problemas comunes (cooperativas, uniones de cooperativas o federaciones de cooperativas) para su visibilidad externa y la defensa de sus intereses en las instituciones y foros representativos, así como los otros fines previstos en el art. 120.1 L.C. ${ }^{13}$, esto es, perseguir los «fines sociales y morales» de la integración cooperativa (Martínez Charterina, 1990: 30-33)

En cualquier caso, el legislador nacional más preocupado por el fomento de la integración cooperativa de carácter económico da un paso en esta línea, aunque limitado a un sector económico muy concreto y abierto a otras estructuras jurídicas productivas distintas de estas sociedades, con la publicación de la Ley 13/2013, de 2 de agosto, de fomento de la integración de cooperativas y de otras entidades asociativas de carácter agroalimentario ${ }^{14}$ que hemos enunciado. Pero esta preocupación del legislador por el fomento de la integración cooperativa económica la extrapola, también, a la de carácter representativo, y la expande con carácter general para todos los sectores económicos con la disposición final segunda, apartado dos de la mencionada Ley 13/2013, por la que modifica el artículo 56.2 de la Ley 27/1999, de 16 de julio, de Cooperativas ${ }^{15}$, en lo relativo al destino de los fondos de educación y promoción cooperativa, que puede emplearse, como hemos señalado anteriormente, como aportación "a favor de la unión o federación de cooperativas en las que esté asociada para el cumplimiento de las funciones que sean coincidentes con las propias del referido fondo".

En relación a las clases de estructuras de colaboración representativa intercooperativa, surge el debate sobre si estas fórmulas jurídicas deben ser consideradas como sociedades o como asociaciones en base al tan traído y llevado

13 Señala el art. 120.1 L.C. que son objetivos de las uniones, federaciones y confederaciones de cooperativas «a) Representar y defender los intereses generales de las cooperativas y de sus socios ante las Administraciones públicas y ante cualesquiera otras personas físicas o jurídicas y ejercer, en su caso, las acciones legales pertinentes. b) Fomentar la promoción y formación cooperativa. c) Ejercer la conciliación en los conflictos surgidos entre las sociedades cooperativas que asocien o entre éstas y sus socios. d) Organizar servicios de asesoramiento, auditorías, asistencia jurídica o técnica y cuantos sean convenientes a los intereses de sus socios. e) Actuar como interlocutores y representantes ante las entidades y organismos públicos. f) Ejercer cualquier otra actividad de naturaleza análoga.».

14 En esta norma se plantea la necesidad de dar instrumentos para redimensionar a este tipo de cooperativas y así pueda tener una mayor presencia en el mercado, instrumentos que concreta en la creación de lo que denomina "Entidad Asociativa Prioritaria", y en el "Plan de Integración Asociativa". Siendo consciente de la dificultad que supone la atomizada competencia legislativa sobre cooperativas que hay en España, plantea soluciones para que la integración que persigue este tipo de empresas suponga la posible actuación económica en el ámbito supra-autonómico (art. 1.1 L. 13/2013). La integración se pretende, por un lado con la publicación del denominado «Plan Estatal de Integración Asociativa» que se presentó para el 2014 y que busca el desarrollo de «una estrategia que les permita superar su actual debilidad, derivada fundamentalmente de su escaso tamaño y su atomización sectorial», Plan que ha sido sustituido por el actual de Integración Asociativa 2015 2020. Por otro lado pretende la potenciación de la integración en este sector con la publicación del R.D. 550/2014, de 27 de junio, en el que se desarrollan los requisitos y el procedimiento para el reconocimiento de las Entidades Asociativas Prioritarias previstas en la Ley 13/2013, concretando qué sea y cómo actuarán estas entidades (Cano Ortega, 2015).

15 Señala la exposición de motivos de la Ley 13/2013, de 2 de agosto, que: «Con objeto de contribuir a la consolidación de las asociaciones de las cooperativas, se plantea la incorporación en el artículo 56 de la Ley 27/1999, de 16 de julio, relativo al Fondo de Educación y Promoción (FEP), de un nuevo párrafo en su punto 2, mediante el que se posibilita expresamente que las cooperativas aporten sus dotaciones del FEP a sus Uniones o Federaciones para el cumplimiento de las funciones que la legislación les tenga encomendadas en la medida en que sean coincidentes con las propias de dichos fondos ». 
requisito del ánimo de lucro ${ }^{16}$ (en este caso por su ausencia) de las uniones, federaciones o confederaciones. Por nuestra parte nos posicionamos dentro de la consideración de sociedad, por descartar la diferenciación sustancial entre ésta y asociación ${ }^{17}$ (Girón Tena, 1976: 31-47). No obstante, cualquier estructura jurídica que no esté concebida para realizar actividades económicas puede ser el marco legal de una organización representativa (Fici, 2014: 116-117).

Centrándonos en el régimen jurídico particular de las distintas estructuras de colaboración representativa que se prevén en la normativa supra-autonómica, sus diferencias radican, fundamentalmente, en que las "uniones" de cooperativas requieren que sus integrantes sean todas cooperativas de la misma clase, con lo que su grado de representatividad está limitado a una actividad económica concreta, sin visión estratégica más allá de la propia de la clase de cooperativas que la integran. Conforme al tenor literal del precepto también se podrán constituir uniones de cooperativas de segundo grado (art. 118 L.C.), lo que ha sido denominado «Uniones de Uniones de Cooperativas» (Romero Candau, 2001: 839).

Las "federaciones" pueden estar formadas por cooperativas, por uniones, o por ambas, pero con un número mayor de miembros y cuyas cooperativas integrantes no podrán ser de una única clase. El ámbito de representación es más amplio, genérico o disperso que el de las uniones de cooperativas, al exigirse que, al menos uno de sus integrantes sea de distinta clase al resto. Deberá tener carácter intersectorial. No parece que se prevea la posibilidad de formar federaciones de segundo grado, puesto que la agrupación de federaciones, solas o con uniones, da lugar a las confederaciones.

Y las "confederaciones" pueden ser la solución a la colaboración extraautonómica, puesto que, como exige el art. 119.4 L.C., tienen que estar formadas, «al menos, [por] tres federaciones de cooperativas que agrupen a cooperativas de, al menos, tres Comunidades Autónomas, aunque la sede de tales federaciones no radique en otras tantas Comunidades». Estas estructuras jurídicas resultan «la patronal cooperativa... la "empresarial cooperativa" y por ello resulta ser el ente

16 En este sentido, Dávila Millán, recogiendo la opinión de Romero Candau, opina que las estructuras de intercooperación representativa son «personas jurídicas de tipo asociativo, no... sociedades, sino asociaciones», en "Asociacionismo y representación...", op. cit., 2013, p. 1068, aunque Romero Candau fundamenta esta naturaleza jurídica de asociación, además, en que las propias cooperativas no son sociedades, sino asociaciones, en "Título III, del asociacionismo cooperativo", en "Cooperativas. Comentarios a la Ley 27/1999, de 16 de julio. Vol. I, Comentarios”, Edit. Colegios Notariales de España, Madrid 2001, p. 839.

17 Respecto a la distinción entre sociedad y asociación, como ya expuso en su día el profesor Girón y posteriormente, entre otros, Paz Ares (1991, 1307-1313), pese a que la doctrina ha solido distinguir entre sociedades y asociaciones en base al carácter económico o no del fin -el lucro, que, no se olvide, es un término que significa «ganancia o provecho que se saca de algo» [R.A.E.] y toda asociación, y toda sociedad persigue un provecho, material o no, para sus miembros, incluso aunque sea de servicio y altruista-, lo cierto es que tanto la sociedad como la asociación tienen la misma naturaleza, la de un cotrato asociativo que se constituye con las aportaciones y/o prestaciones que realicen sus componentes -socios o asociaciados-, para el desarrollo de una actividad que les satisface, si bien es cierto que con distinto régimen jurídico y, sobre todo, régimen de control, uno técnico para las sociedades y otro político para las asociaciones, derivado del temor del legislador liberal francés a la hora de regular las agrupaciones de personas, puesto que sabe que aquellas que buscan el beneficio económico no suelen enfrentarse al poder -las sociedades-, en cambio las que no buscan ese fin han de estar controladas por la propia administración -las asociaciones-. Esta artificiosa diferenciación del legislador liberal francés es la que se importó a nuestro régimen jurídico, buscando una justificación estructural y de naturaleza distinta. La distinción real en cuanto a la naturaleza y concepción de las personas jurídicas sí se aprecia entre la asociación y las fundaciones, pero no entre las asociaciones y las sociedades. 
representativo de las Cooperativas...[que] ha de ser el "lobby" del Cooperativismo... [actuando] en los círculos económicos, politicos y sociales, tanto en el interior como en el exterior» (Divar, 1997: 28).

\subsection{Intercooperación representativa en el ámbito autonómico}

Estas fórmulas de integración intercooperativa representativa prevista en la Ley de ámbito estatal se corresponde con las previstas en las distintas normas autonómicas ${ }^{18}$, contemplando algunas de éstas las mismas fórmulas de colaboración representativa que la nacional, otras eludiendo alguna de las allí previstas, las hay que exigen la presencia de integrantes de las estructuras asociativas de miembros con domicilio social en distintas provincias de su comunidad $^{19}$, y todas exigiendo un número mínimo de integrantes en las distintas fórmulas intercooperativas, o admitiendo a entidades jurídicas distintas de las cooperativas, incluso que no se correspondan con las propias de la economía social $^{20}$, pero sin excluir en ninguna de ellas cualquier fórmula de asociacionismo representativo que pudiera darse. Lo que no contemplan las normas autonómicas de cooperativas es la posibilidad de colaboración extra-autonómica representativa, lo que puede ser un problema de alcance en la proyección y defensa de los intereses de las cooperativas que buscan su representatividad y visibilidad en un mercado cada vez más global, y les obliga a buscarla fuera de su marco legal.

El funcionamiento de las federaciones de un ámbito autonómico como en Andalucía es distinto al pergeñado a nivel nacional. En Andalucía, las "federaciones" se constituyen sin variación sectorial de cooperativas, pudiendo integrarse por cooperativas de la misma clase y, en las agrarias, con sociedades agrarias de transformación y agrupaciones de productores agrarios que no tengan la condición de sociedades cooperativas, aunque no deberán a llegar a la mayoría de miembros de la federación (art. 111.2 L.S.C.A.). Federaciones como FAECA Federación Andaluza de Empresas Cooperativas Agrarias-, FAECTA -Federación Andaluza de Empresas Cooperativas de Trabajo Asociado-, FEDECCON Federación Andaluza de Cooperativas de Consumidores y Usuarios-, o EMCOFEANTRAN -Empresas Cooperativas Federadas Andaluzas de Transporte, son federaciones sectoriales de cooperativas de la misma clase. Para incorporar cooperativas de otros sectores, habrán de fundarse asociaciones de federaciones.

Respecto a las "confederaciones" (en la legislación autonómica cooperativa andaluza serían las "asociaciones" de federaciones -art. 113.1 L.S.C.A.-) sí que

18 En este sentido, Vid. Dávila Millán, en "Asociacionismo y representación del movimiento cooperativo", en Tratado de Derecho de Cooperativas, Tomo II, AAVV, dir. Peinado García, Coord. Vázquez Ruano, Edt. Tirant Lo Blanch, 2013, pp. 1062-1067, quien hace una enumeración de los preceptos y contenido de las distintas leyes autonómicas que recogen el asociacionismo representativo de las cooperativas, pero, por razón de la fecha de publicación, no recoge los preceptos de la Ley 6/2013, de 6 de noviembre, de Cooperativas de Cantabria, que lo regula en sus artículos 149 a 153.

19 En la Ley de Cooperativas Andaluza se exige la presencia en las federaciones de ámbito "regional" (término en desuso por el de "autonómico") de al menos cinco provincias de su Comunidad (art. 113.2).

20 Como en el caso de la Ley de Cooperativas de la Comunidad de Madrid, que permite, en su artículo 139.4, agrupar «incluso a las que no tienen carácter cooperativo, ni pertenecen a la economía social, siempre que el conjunto de las entidades cooperativas ostente la mayoría»; o en el texto refundido de la Ley de Cooperativas de Aragón, que permite la inclusión en las confederaciones de cooperativas a las Sociedades Agrarias de Transformación (art. 93.9). 
tienen un carácter intersectorial, admitiendo federaciones, asociaciones de base, coordinadoras, uniones de profesionales, o empresas y entidades de la economía social y que se aglutinaban todas en la prácticamente desaparecida organización empresarial CEPES-Andalucía ${ }^{21}$, que se denominaba como "Confederación" de entidades para la economía social, término que no existe en la legislación andaluza, ni se corresponde con la nacional, puesto que operaba solo en una comunidad autónoma.

En el ámbito nacional, distintas organizaciones representativas del ámbito autonómico se insertan fuera del mismo, incluso en el internacional. Así, actualmente son miembros nacionales de la A.C.I., la denominada «asociación de asociaciones de cooperativas» (Gadea, Sacristán y Vargas, 2009: 540), cinco entidades, de las cuales dos son de ámbito puramente autonómico: la Confederació de Cooperativas de Catalunya (CoopCat), y la Confederación de Cooperativas de Euskadi (KONFEKOOP). Y las otras tres son la Fundación Espriu, la Confederación de Cooperativas de Trabajo Asociado (COCETA), y la Confederación Empresarial Española de la Economía Social (CEPES) 22 , estando todas ellas, las de ámbito autonómico y las otras dos siguientes integradas, a su vez, en la última. Lo que resulta evidente es que el corsé legal no evita el desborde de la realidad.

\subsection{La integración empresarial representativa no cooperativa}

Fuera del ámbito cooperativo y de la economía social, la colaboración representativa en el marco nacional de otros agentes económicos, los empresarios capitalistas, incluidos los autónomos -que en Andalucía también se incluyen en la economía social ${ }^{23}$, se canaliza por las Cámaras Oficiales de Comercio, Industria, Servicios y Navegación, entidades corporaciones- «de derecho público que realizan funciones de carácter consultivo y de colaboración con las Administraciones Públicas en todo aquello que tenga relación con la representación, promoción y defensa de los intereses generales del comercio, la industria, la navegación y los servicios» ${ }^{24}$. Estas cámaras oficiales nacen en España a finales del siglo XIX, regulándose por primera vez en $1886^{25}$. En 1919 se constituyó la denominada Cámara de Comercio Internacional (C.C.I.), a imagen de la constitución de la Alianza Cooperativa Internacional (1895), y posteriormente, en 1922, lo hizo el Comité Español de la Cámara de Comercio Internacional. Las funciones de la C.C.I. se centran en «dos grandes campos de actuación: el de sensibilización e influencia cerca de las instancias internacionales que afectan al comercio y a la

22

http://ica.coop/en/directory/members?action=civi_members_search\&current_page=1\&name=\&location=coun try-1198\&sector $=\&$ structure.

23 La Federación Andaluza de Atónomos (CEAT-Andalucía) formaba parte de CEPES-Andalucía, y en cambio, la Federación Nacional de Autónomos (CEAT) no forma parte de CEPES nacional.

24 Preámbulo de la Ley 4/2014, de 1 de abril, Básica de las Cámaras Oficiales de Comercio, Industria, Servicios y Navegación, que luego se desarrolla en los artículos $2^{\circ}, 3^{\circ}$ y $5^{\circ}$ de la misma norma.

25 En el propio preámbulo de la Ley 4/2014 se hace una exposición detallada del régimen jurídico de las Cámaras en España. 
inversión, y el de ofrecer servicios útiles a las empresas» ${ }^{26}$. Esta institución, aunque tiene como fin la elaboración de «una Carta de las Empresas para un Desarrollo Sostenible», y pretende la «Creación de un Consejo Mundial de la Industria para el Medio Ambiente», lo cierto es que no contempla un interés similar al que persigue la A.C.I. en pos de dotar de un contenido ético y formal a la acción que han de desarrollar sus integrantes como una opción de desarrollo económico bajo parámetros democráticos y de desarrollo sostenible para la sociedad y el entorno social y medio-ambiental. Los principios de actuación de las empresas capitalistas no necesitan ser fijados de forma concreta como en el caso de las cooperativas (Fici, 2014: 111), puesto que toda la realidad de nuestro entorno económico no es sino reflejo del pensamiento liberal. Señalar unos principios de actuación de las sociedades capitalistas sería como describir nuestra realidad. En el ámbito europeo, la Cámara de Comercio de España forma parte de la Asociación Europea de Cámaras de Comercio e Industria, que es miembro del Grupo I de Empresarios del Comité Económico y Social Europeo (CESE) ${ }^{27}$, lo que, como veremos, resulta relevante a los efectos que aquí nos trae.

Otra fórmula de integración representativa de las empresas llamadas capitalistas son las confederaciones empresariales provinciales, que se proyectan en distintas organizaciones igualmente representativas de ámbito autonómico como puede ser la Confederación de Empresarios de Andalucía $(\mathrm{CEA})^{28}$, o a nivel estatal como pueden ser la Confederación Española de Organizaciones Empresariales (CEOE) ${ }^{29}$, o la Confederación Española de la Pequeña y Mediana Empresa (CEPYME) ${ }^{30}$, y de ahí, al ámbito de la Unión Europea, participando la CEOE en el seno de la BUSINESSEUROP, y la CEPYME en la UEAPME, que igualmente resultan miembros del Comité Económico y Social Europeo (CESE) ${ }^{31}$.

\subsection{Miscelánea en la integración representativa}

En el ámbito de la colaboración o integración representativa de empresas no hay dos realidades paralelas, una para las cooperativas ${ }^{32}$ y otra para las capitalistas, sino que se producen fusiones, interrelaciones entre las sociedades cooperativas y cualquier otra tipología societaria, incluso distinta al ámbito propio de la economía social. Prueba de ello son las organizaciones y asociaciones de productores de frutas y hortalizas que veremos más adelante, o la participación en el propio seno del Comité Económico y Social de la Unión Europea (CESE), en su Grupo III ${ }^{33}$, que hemos enunciado, donde «funcionan diversas categorias, una de las cuales es

26 Así se expresa en la página oficial del Comité Español de la Cámara de Comercio Internacional. http://www.iccspain.org/index.php?option=com_content\&view=section\&id=3\&Itemid $=41$.

27 Vid. página oficial del CESE http://www.eesc.europa.eu/en/members-groups/groups/employersgroup/partner-organisations?field_partner_organisation_type_target_id=5473\&name_list=All

28 Vid. página oficial de CEA http://www.cea.es/portal/miembros/miembros1.aspx.

29 Vid. página oficial de CEOE http://www.ceoe.es/es/empresas.

30 Vid. página oficial de CEPYME http://www.cepyme.es/es/que-es-cepyme/.

31 Vid. página oficial http://www.eesc.europa.eu/en/members-groups/groups/employers-group/partnerorganisations?field_partner_organisation_type_target_id=5473\&name_list=All

32 Aunque no obstante existen una ingente panoplia de entidades representativas del puro ámbito cooperativo tanto a nivel nacional como europeo. En este sentido Vid. Valdés Dal-Ré, 2009.

33 Vid. página oficial del CESE http://memberspage.eesc.europa.eu/Vademecum/Home 
la de "economía social", integrada por representantes de las cuatro grandes y tradicionales familia de la economía social (cooperativas, mutualismo, asociaciones y fundaciones) así como diversas Organizaciones No Gubernamentales (ONG) dotadas de una resuelta vocación social» (Valdés DalRé, 2009: 43), convergiendo en un mismo organismo con proyección europea entidades e intereses puramente capitalistas con otros propios de la economía social.

Casos puntuales de participación de cooperativas concretas en estructuras representativas no cooperativas sería el de ANECOOP, miembro de la Asociación Valenciana de Empresarios (AVE), que participó con el Círculo de Empresarios de Madrid, el Club Financiero de Vigo o el Observatorio Económico de Andalucía fundando el Grupo de Economía y Sociedad; o con presencia en la Confederación Empresarial Valenciana (CEV); o en la asociación empresarial $\mathrm{AECOC}^{34}$. Igualmente, la Corporación Mondragón es un claro ejemplo de esta interrelación empresarial, de la que forman parte hasta un total de doscientas sesenta y una empresas y entidades, en las que figuran tanto cooperativas como sociedades puramente capitalistas tanto de ámbito nacional como internacional ${ }^{35}$. Es decir, que de la intercooperación en el puro ámbito cooperativo, se ha pasado a la intercooperación empresarial, formándose «una red de organismos y organizaciones... en forma de una rica maraña cada vez más compacta y diversificada» (García Gallardo, 1979: 119), aunque formada y participada por cooperativas junto a otras estructuras de empresas de distinta naturaleza jurídica, lo que desdibuja el planteamiento de proyección del modelo cooperativo en aras de utilizar, participar y estar presente en los ámbitos de decisión empresarial, sin el calificativo de capitalista o cooperativo.

\section{Otras fórmulas legislativas e institucionales de la intercooperación representativa fuera del ámbito cooperativo}

\subsection{El caso de las OPFH}

Un paso político y legislativo en torno a la potenciación y fortalecimiento de las estructuras representativas de las cooperativas fuera del estricto marco legal cooperativo es el desarrollo legislativo nacional de los Reglamentos de la Unión Europea referentes a las Organizaciones de Productores de frutas y hortalizas. La Orden de 30 de abril de 1997, sobre reconocimiento de organizaciones de productores de frutas y hortalizas, fue el desarrollo legislativo nacional del Reglamento de la Comunidad Europea número 2200/96, del Consejo, de 28 de octubre, donde se fijan la condiciones y requisitos para que las organizaciones de productores puedan ser reconocidas por los Estados miembros, y del Reglamento (CE) 412/97, de la Comisión, de 3 de marzo, que enuncia como posible organización de productores a las cooperativas, sociedades agrarias de transformación, sociedad mercantil u otro tipo de entidad. Y lo cierto es que, para

34 Vid. página oficial de ANECOOP: http://anecoop.com/sobre-nosotros/presencia-institucional/

35 Vid. http://www.mondragon-corporation.com/nuestros-negocios/empresas-y-cooperativas/ 
dar cumplimiento al requisito exigido por el Reglamento 2200/96 de que en los estatutos de las organizaciones de productores contengan «las reglas que garanticen, de forma democrática, a los productores asociados el control de su organización y de las decisiones de ésta» (art. 11.d.3), la Orden de 1997 se centra en las cooperativas y SAT, exigiendo mayores requisitos a las demás tipologías sociales. No obstante, pese a reconocerse en el Reglamento CE 2200/96 la existencia de las "asociaciones de organizaciones de productores", en la Orden nacional de 1997 no se hace mención alguna a tal posibilidad asociativa.

Con el Real Decreto 1972/2008, de 28 de noviembre, desarrollo legislativo nacional de los reglamentos comunitarios (CE) 1182/2007 del Consejo, de 26 de septiembre, sustituto del Reglamento 2200/96, y el Reglamento 1580/2007, de la Comisión, de 21 de diciembre, que deroga el Reglamento 1943/2003 de la Comisión, que modificó el Reglamento (CE) 412/97, se reconoce la existencia de asociaciones de organizaciones de productores nacionales y transnacionales (arts. 13 a 15 RD 1972/2008). En esta norma interna se perfila a las cooperativas y SAT como las estructuras jurídicas que de forma natural formarán las organizaciones de productores, exigiendo requisitos y garantías a las otras fórmulas jurídicas que se constituyan como tales. Consecuente con esta premisa, las asociaciones de organizaciones de productores estarán formadas, fundamentalmente, por cooperativas y SAT, y las funciones que se asignan a estas asociaciones (art. 14 RD 1182/2007) son, entre otras, de adiestramiento en producción, comercialización y promoción común de sus integrantes, lo que supone una manifestación de la integración representativa.

Con la reforma de los enunciados reglamentos comunitarios por los vigentes (UE) $n^{\circ} 1308 / 2013$, del Parlamento Europeo y del Consejo, de 17 de diciembre, y el (UE) 2017/891, de la Comisión, de 13 de marzo, a nivel interno nacional se ha publicado el RD 532/2017, de 26 de mayo, por el que se regulan el reconocimiento $\mathrm{y}$ funcionamiento de las organizaciones de productores del sector de frutas y hortalizas y que deroga el anterior RD 1972/2008, de 28 de noviembre, y cuyo articulado viene a reforzar la naturalidad de la estructura jurídica de las cooperativas y las SAT para constituir organizaciones de productores en el sector, así como para las asociaciones de estos, previendo para la que denomina "sociedad mercantil" -capitalista- determinadas prevenciones como el que sus participaciones -que siempre lo son-, o acciones sean nominativas. En cualquier caso, la idoneidad de las cooperativas y SAT respecto a las sociedades capitalistas en la formación de organizaciones de productores y sus asociaciones deviene, fundamentalmente, por la facilidad intrínseca de aquellas en aglutinar personassocios -que serán productores-, frente a éstas cuyos socios unos podrán ser productores y otros meros inversores. En el articulado del R.D. 532/2017 se regula a las asociaciones de organizaciones de productores, previendo su composición en entidades jurídicas -sin determinar que sean asociaciones o sociedades de cualquier tipología-, o en una sección de cooperativa o de una SAT (art. 16), con lo que, de natural, serán estas tipologías sociales quienes están llamadas a formar las asociaciones de organizaciones de productores. De hecho, en la página oficial del Ministerio de Agricultura está publicada la relación nominal de organizaciones de 
productores de frutas y hortalizas, y, en concreto, a fecha 1 de mayo de $2017^{36}$, del total de quinientas setenta y una Organizaciones de Productores inscritas, solo cincuenta y tres son sociedades de responsabilidad limitada, cuatro son sociedades anónimas -todas de la Comunidad Autónoma de Murcia-, y del resto, doscientas veinticuatro son SAT y doscientas noventa son cooperativas, con lo que la proporción de "sociedades mercantiles" -capitalistas- es más que escasa respecto a las cooperativas y SAT, lo que es muestra de que estas últimas tipologías sociales son el destinatario natural de este tipo de legislación. Sin embargo, en lo que se refiere a Asociaciones de Organizaciones de Productores inscritas en el Ministerio de Agricultura, a la misma fecha 1 de mayo de $2017^{37}$, solo hay nueve, y dos de ellas con estructura de sociedad anónima, quizá por el desarrollo legislativo y experiencia en la práctica societaria de este tipo de sociedad.

Si bien es cierto que las organizaciones de productores y sus asociaciones podrían considerarse instrumentos de la intercooperación de carácter económico para las cooperativas, lo relevante es que entre las funciones asignadas a éstas últimas están las propias de una estructura pensada para asociar, aglutinar a distintas organizaciones de productores para mejora de las condiciones, defensa de sus intereses y promoción de sus miembros y productos, con lo que suponen un instrumento propio de la integración representativa, que centrada en las cooperativas está al servicio de la intercooperación representativa. De hecho, en el art. 18 del RD 532/2017 concreta el legislador nacional las funciones de las Asociación de Organizaciones de Productores en torno a la defensa, promoción y proyección de sus miembros.

\subsection{Ley de la Economía Social}

Otra manifestación de la expansión de la intercooperación representativa es la prevista en el ámbito legislativo e institucional genérico de la Economía Social. No hay que olvidar que las cooperativas han sido calificadas por la Ley 5/2011, de 29 de marzo, de Economía Social (art. 5.1), como la primera de las denominadas entidades de la Economía Social, con lo que le es de aplicación todo el régimen jurídico y medidas de apoyo que se prevean para este tipo de estructuras jurídicas. Y entre esas medidas de apoyo y promoción la propia Ley 5/2011 establece en su artículo 7 que «Las entidades de la economía social podrán constituir asociaciones para la representación y defensa de sus intereses, y estas podrán agruparse entre sí», fijando los requisitos para constituir las confederaciones intersectoriales de ámbito estatal representativas ${ }^{38}$, que han ido siendo desarrollados por distintas disposiciones legales como las resoluciones de 19 de agosto de 2014, del Servicio Público de Empleo Estatal, o la de 25 de agosto del mismo año, de la Dirección

36 http://www.mapama.gob.es/es/agricultura/temas/regulacion-de-los-mercados/listadoopsmayo2017_tcm7458373.pdf.

37 http://www.mapama.gob.es/es/agricultura/temas/regulacion-de-los-mercados/listadoaopsmayo2017_tcm7458372.pdf.

38 No obstante el uso del plural en el precepto: "Confederaciones Intersectoriales", puede dar idea de un número relativamente elevado de éstas para intervenir en la representación y defensa de los intereses de las entidades de la economía social, lo cierto es que con los requisitos que exige el propio art. 7.2 L. 5/2011, «el legislador estatal opta por pocas, y potentes, asociaciones intersectoriales estatales representativas» (Paniagua Zurera, 2011: 252), básicamente CEPES. 
General del Trabajo Autónomo, de la Economía Social y de la Responsabilidad Social de las Empresas, que fijan los requisitos de estas entidades representativas para acceder a subvenciones públicas para el empleo ${ }^{39}$.

Igualmente, en el marco nacional e internacional de fomento de las entidades de la economía social, el Programa de Fomento e Impulso de la Economía Social 2015-16, publicado por la Dirección General del Trabajo Autónomo, de la Economía Social y la Responsabilidad Social de las Empresas, desarrollado en coordinación con el Plan Estatal de Integración Asociativa 2015-2020, fijó como objetivo en su Eje 1 de impulso a la creación y fortalecimiento de las entidades de la economía social, el dar protagonismo a sus organizaciones representativas en el diseño de la formación para el empleo, y en su Eje 4 de desarrollo de la economía social en el marco de la agenda europea y mediterránea, la puesta en marcha del Programa Operativo del Fondo Social Europeo de Inclusión Social y Economía Social 2014-2020, que ha fijado como programa operativo en España el de Inclusión social y de la Economía Social, donde tienen una relevancia especial las organizaciones representativas de la economía social (arts. 7 y 8 L. 5/2011, de 29 de marzo).

\subsection{Organizaciones Interprofesionales Agroalimentarias}

Y, finalmente, otra manifestación de la interrelación representativa cooperativa con entidades empresariales de carácter capitalista a nivel nacional, también al margen de la legislación cooperativa, son las denominadas Organizaciones Interprofesionales Agroalimentarias, reguladas en la Ley 38/1994, de 30 de diciembre, son un ejemplo de interrelación representativa entre sociedades cooperativas y capitalistas, puesto que necesitan para su reconocimiento institucional distintos porcentajes de producción, transformación o comercialización a nivel autonómico y nacional en el ámbito agroalimentario, con lo que dada la trascendencia que en este sector económico tienen las cooperativas han de colaborar institucionalmente con otras personas jurídicas que se dedican a la misma actividad para la promoción y defensa de su sector conforme prevé su art. 3 tras la reforma operada por la disposición final primera de la Ley 12/2013, de 2 de agosto, de medidas para mejorar el funcionamiento e la cadena alimentaria.

\section{Conclusiones}

La manifestación representativa del principio de cooperación entre cooperativas ha tenido un reconocimiento real que no se inicia con su enunciación formal por la A.C.I. en 1995, ni en la anterior de 1966, puesto que es consustancial con el movimiento cooperativo, origen y marco de las sociedades cooperativas y de su regulación.

39 Con anterioridad a la publicación de la Ley 5/2011, de Economía Social, ya se contemplaban competencias públicas a las "organizaciones representativas de la economía social de carácter intersectorial", que junto con las federaciones y confederaciones de cooperativas, pero distintas a ellas, podían ser sujetos beneficiarios de subvenciones destinadas al subsistema de formación profesional para el empleo, tal y como regulaba la Orden TAS/718/2008, de 7 de marzo. 
En la política legislativa nacional, la intercooperación representativa ha tenido un desigual tratamiento, fundamentalmente en el período de la dictadura franquista que fue, de hecho, sustituida por el férreo control político del gobierno, lo que supuso la exclusión de entidades representativas del cooperativismo en España del marco internacional. Con la democracia, se potenció el marco legal de la intercooperación representativa, pero surgió el nuevo problema de la atomización legislativa autonómica, que contempla diversas y variadas estructuras de representación y defensa de los intereses de las cooperativas, pero que no alcanzan, legislativamente, más allá de su correspondiente ámbito territorial autonómico.

Al margen del marco jurídico puramente cooperativo, el legislador nacional ha ido publicando normativa de diversa índole que potencia, de forma indirecta a las entidades representativas de las sociedades cooperativas al darles protagonismo a las que operan en campos económicos especialmente participados por aquellas, como son las asociaciones de organizaciones de productores de frutas y hortalizas; o las Confederaciones Intersectoriales representativas en el marco de la promoción de la economía social; o la potenciación de las Organizaciones interprofesionales agroalimentarias. Todos marcos legales de potenciación de las entidades representativas de empresas de sectores donde las cooperativas tienen un papel especialmente relevante.

Pese a que formalmente pueda parecer que el asociacionismo cooperativo dista mucho del que pueden utilizar las empresas capitalistas, la realidad lo desmiente puesto que para las primeras se regula la existencia de uniones, federaciones y confederaciones, con distintos requisitos según el régimen autonómico o nacional, y de ahí, a la representación institucional a nivel europeo (CESE), y, finalmente, a nivel mundial (A.C.I.), y, en paralelo, las sociedades de capital y el resto de operadores económicos, sin que haya previsión legal específica, se organizan en asociaciones e instituciones de representación como son las Cámaras de Comercio, Industria y Navegación, o en asociaciones profesionales de ámbito provincial, autonómico y nacional, y de ahí al ámbito de la Unión Europea (CESE), y, a nivel mundial (C.C.I.). Convergiendo las sociedades cooperativas y las capitalistas en organismos internaciones de primer orden como el Comité Económico y Social Europeo.

La realidad es más compleja y rica que el marco legal que la contempla, de tal manera que se forman confederaciones cooperativas de ámbito autonómico, participaciones de organizaciones de representación cooperativa en entidades de representación capitalista, y formación de entidades de representación empresarial sin distinción de tipología societaria de sus miembros, tanto a nivel nacional como internacional, y ello, unas veces con respaldo jurídico, y otras con el respaldo de la oportunidad y conveniencia, al margen del purismo cooperativista. Es la maraña compacta y diversificada de la que hablaba García Gallardo, pero mucho más compleja y que acerca las distintas estructuras jurídicas produciéndose un isomorfismo mutuo, que en definitiva hace que el sexto principio internacional cooperativo que debe actuar como ancla que impida que el barco cooperativo derive en exceso impulsado por los vientos o arrastrado por las corrientes de la economía capitalista y pueda conservar su propia identidad en nuestra legislación nacional, a que se refiere Vargas Vasserot, como mínimo está garreando. 


\section{Referencias bibliográficas}

Alfonso Sánchez, R. (2003) Posibilidades y regulación de los procesos de integración en España (Cooperativas de Segundo Grado, Grupos Cooperativos, Fusiones), en:

Namorado, R.; Chaves, R. y Fajardo, G. (Coords) Integración Empresarial Cooperativa. Posibilidades, ventajas inconvenientes, Ponencias del $\mathrm{II}^{\mathrm{o}}$ coloquio ibérico de cooperativismo y economía social, Ciriec-España, pp. 19-42.

Alfonso Sánchez, R. (2009) La legislación española sobre cooperativas y sociedades laborales: ¿Una respuesta adecuada a las necesidades del sector?. Ciriec. Revista Jurídica de Economía Social y Cooperativa, No 20, pp. 9-41.

Alfonso Sánchez, R. (2015) Los principios cooperativos configuradotes de la forma social cooperativa, Ciriec. Revista Jurídica de Economía Social y Cooperativa, No 27, pp. 4985.

Alonso Sebastián, R. (1982) Principios cooperativos y cooperativas mercantilizadas: un caso real de la industria azucarera, Revista Agricultura y Sociedad, No 25, pp. 141-181.

Aymerich Cruells, J. (2008) Las cooperativas y las colectivizaciones obreras en Catalunya como modelos de gestión colectiva. Proceso de regulación legal (1839-1939), Tesis doctoral. Disponible en http://www.tdx.cat/bitstream/handle/10803/1409/JAC_TESIS.pdf.txt;jsessionid=EE2EF E7CBB25511CA33DBB2A6AA75B5E? sequence=2.

Aranzadi Tellería, D. (1976) Cooperativismo industrial como sistema, empresa y experiencia, Universidad de Deusto, Bilbao.

Cano Ortega, C. (2015) Hacia la calificación como entidad asociativa prioritaria: las diferentes formas de integración de las cooperativas agroalimentarias, REVESCO. Revista de Estudios Cooperativos, Segundo Cuatrimestre, No 118, pp. 60-85. DOI: 10.5209/rev_REVE.2015.n118.49064.

CONFEDERACIÓ DE COOPERATIVES DE CATALUNYA (2016) De l'estat liberal a l'Estatut d'Autonomia. De l'estat liberal al franquisme. Disponible en http://www.cooperativescatalunya.coop/index.php/ca/observatori/historia.

Dávila Millán, E. (2013) Asociacionismo y representación del movimiento cooperativo, en Tratado de Derecho de Cooperativas, Tomo II, AA.VV., Director Peinado García, Coordinadora Vázquez Ruano, pp. 1061-1074. Valencia: Tirant Lo Blanch.

De Miranda, J.E. (2014) De la propedéutica de los principios cooperativos a la intercooperación como pilastra del cooperativismo, Boletín de la Asociación Internacional de Derecho Cooperativo, $\mathrm{N}^{\circ} 48$, pp. 149-163.

Divar Garteiz-Aurrecoa, J. (1997) La Confederación de Cooperativas en Euskadi, Boletín Asociación Internacional de Derecho Cooperativo, No 27, pp. 27-30.

Fernández Navarrete, D. (2005) La política económica exterior del franquismo: del aislamiento a la apertura, Historia Contemporánea, $\mathrm{N}^{\mathrm{o}} 30$, pp. 49-78.

Fici, A. (2014) La cooperación entre cooperativas en el Derecho Italiano y comparado, Boletín de la Asociación Internacional de Derecho Cooperativo, № 48, pp. 103-148.

Gadea, E.; Sacristán, F. y Vargas Vasserot, C. (2009) Régimen Jurídico de la Sociedad Cooperativa del Siglo XXI. Realidad actual y propuestas de reforma. Madrid: Dykinson, S.L.

García Gallardo, M. (1979) La Organización Internacional del Cooperativismo. REVESCO. Revista de Estudios Cooperativos, № 49, pp. 119-134.

García-Gutiérrez Fernández, C. (1995) Las sociedades cooperativas de derecho y las de hecho con arreglo a los valores y a los principios del Congreso de la Alianza Cooperativa Internacional de Manchester de 1995: especial referencia a las sociedades 
de responsabilidad limitada reguladas en España. REVESCO. Revista de Estudios Cooperativos, $\mathrm{N}^{\mathrm{o}}$ 61, pp. 53-88.

Girón Tena, J. (1976) Derecho de Sociedades. Tomo I, Madrid: SN.

Macías Ruano, A.J. (2015) El Quinto Principio Internacional Cooperativo: Educación, formación e información. Proyección legislativa en España. Ciriec. Revista Jurídica de Economía Social y Cooperativa, $\mathrm{N}^{\mathrm{o}} 27$, pp. 243-284.

Martínez Charterina, A. (1990) Análisis de la Intercooperación Cooperativa, Deusto: Edit. Universidad de Deusto.

Martínez Charterina, A. (2012) Sobre el principio de cooperación entre cooperativas en la actualidad, Boletín de la Asociación Internacional de Derecho Cooperativo, No 46, pp. 133-146.

Moreno Fontela, J.L. (2017) Las relaciones entre los valores y principios cooperativos y los principios de la normativa cooperativa. REVESCO. Revista de Estudios Cooperativos, Segundo Cuatrimestre, No 124, pp. 114-127. DOI: 10.5209/REVE.54923.

Mozas Moral, A. y Puentes Poyatos, R. (2010) La responsabilidad social corporativa y su paralelismo con las sociedades cooperativas. REVESCO. Revista de Estudios Cooperativos, Tercer Cuatrimestre, № 103, pp. 75-100.

Paniagua Zurera, M. (2011) Las empresas de la Economía Social. Más allá del comentario a la Ley 5/2011, de Economía Social, Edit. Marcial Pons.

Paz Ares, C. (1991) Título VIII. De la sociedad, artículos 1665 a 1708, Comentario del Código Civil, AA.VV., Madrid: Ministerio de Justicia, pp. 1299-1523.

Paz Canalejo, N. (1995) Principios Cooperativos y prácticas societarias de la cooperación. REVESCO. Revista de Estudios Cooperativos, № 61, pp. 15-33

Romero Candau, P.A. (2001) Título III, del asociacionismo cooperativo, en Cooperativas. Comentarios a la Ley 27/1999, de 16 de julio, Vol. I, AA.VV. Madrid: Colegios Notariales de España, pp. 837-843.

Sánchez Pachón, L.A. (2015) Modalidades de integración y colaboración de las cooperativas en Castilla y León y perspectivas de desarrollo, Revista Jurídica de Castilla y León, $\mathrm{N}^{\mathrm{o}} 36$.

Santos Domínguez, M.A. (2015) La relación de los principios cooperativos con el derecho. Ciriec. Revista Jurídica de Economía Social y Cooperativa, № 27, pp. 87-132.

Sanz Jarque, J. J. (1994) Cooperación. Teoría General y Régimen de las Sociedades Cooperativas. El nuevo Derecho Cooperativo, Edit. Comares.

Valdés Dal-Ré, F. (2009) La representación institucional de la economía social: una aproximación desde el derecho vigente y desde el derecho propuesto. Ciriec-España. Revista de Economía Pública, Social y Cooperativa. No 66, pp. 37-60.

Vargas Vasserot, C. (2016) Prólogo, en Las sociedades cooperativas y la adaptación de sus principios al mercado, Edit. Cajamar-Caja Rural, pp. 11-16. 